\title{
Research on the Coordinated Relations between Population and Land in the Urbanization Process of Hebei
}

\author{
YAN Qiaona ${ }^{1}$, QV Zhanbo ${ }^{2}$, MA Shuai ${ }^{1}$, WANG Yinchuan $^{1}$
}

1. College of Land and Resources, Agricultural University of Hebei, Baoding, Hebei, 071000;

2. Hebei Institute of Urban and Rural Planning and Design, Shijiazhuang, Hebei, 050051

Keywords: Hebei province; city; population; land

\begin{abstract}
Urbanization is one of main reasons for world progress and development. In order to understand the urban population size of Hebei as well as land scale development law and status, this paper analyzes the coordinated relationship between urban population and land to guide the future urban development. The time span in this paper is 13 years from 2000 to 2012 and the allometic growth and urban land expansion parameters are adopted to analyze their relationship from the levels of time and space. The results show that Hebei urban system is not perfect and the urban size is small. From vertical perspective, the allometric relationship of the whole province was gradually significant from 2006, and the growth rate of built-up area was significantly higher than that of urban population. From horizontal perspective, the land expansion coefficients of most cities were higher than the reasonable value, the urban population density was low, and land use efficiency had yet to be improved.
\end{abstract}

\section{Classification No.: F2932 Document Code: A}

\section{Introduction}

Urbanization is one of the main driving forces of world development as well as a symbol of civilization of a region ${ }^{[1]}$. It refers to a process of rural population and land transformed to urban population and land, with the changes of social relations, economic relations and lifestyle ${ }^{[2]}$. In 2012, China's urbanization rate was 52.57\%, while Hebei's urbanization rate was only $46.80 \%$. In the process of population and land flowing to cities, population urbanization and land urbanization are formed, which have a close relationship. Firstly, due to the attractiveness of economic development, population flows to cities, so population increase leads to land flow to cities. Whether their development relationship is coordinated is increasingly attracting attention. At present, in China, there are many researches on urban population and land, while there are few researches on their coordination relationship. In the national scale, Tan Shukui etc. studied the matching state of land urbanization and population urbanization ${ }^{[3]}$; Zhao Cen etc. studied the mutual relationships

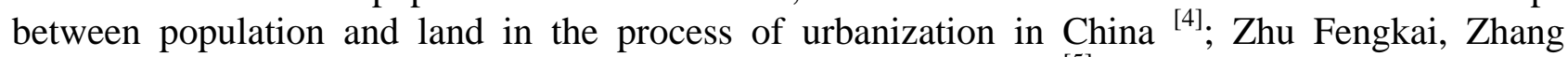
Fengrong etc. studied coordination degree and regional difference ${ }^{[5]}$. In the provincial scale, there were researches in Xinjiang, Guangdong and Shandong Peninsula ${ }^{[6-8]}$. This paper used the allometic growth and urban land expansion parameter to analyze their relationship from the level of time and space so as to reveal the development states of urbanization of population and land in Hebei province.

\section{Overview of Research Area and Data Source}

Overview of Research Area. The geographic location of Hebei province is east longitude $113^{\circ} 04^{\prime}$ to $119^{\circ} 53^{\prime}$ and north latitude $36^{\circ} 01^{\prime}$ to $42^{\circ} 37^{\prime}$. It is located in the North China Plain and surrounds two major cities-Beijing and Tianjin. With a long history, it is the birthplace of the Chinese nation. It has a monsoon climate of medium latitudes. In winter, it is cold and dry; in summer, it is hot and humid. The landforms are various and resources are rich, especially mineral and marine beach resources. It covers an area of the province $187,693 \mathrm{~km}^{2}$ and has a population of 72.8751 million (2012). In the administrative region, it has 11 prefecture-level cities, 22 county-level cities, 108 counties and 6 autonomous counties. 
Data Source.The basic data in this paper is from Annual Statistical Report on Construction of Cities and Counties in Hebei (2001-2013). Compared with data of each year, it is found that on February 1, 2002, County-level Fengnan City was removed upon approval of the State Council (Guohan [2002] No.7), and the Fengnan District, Tangshan City was established. From 2002, there was no statistical data about Fengnan City, Therefore, it is removed from data. The population data in this paper is not about non-agricultural population but about urban population. The reason is the limit of existing household registration system. The gap between non-agricultural population and actual population living in cities has gradually widened. If the non-agricultural population data is used as basic data for research, it has little practical significance.

\section{Research on Relationship of Scale Expansion between Urban Population and Land}

The urban population and built-up area of Hebei province increase by a large amplitude from2000 to 2012. Figure 1 shows that the increasing range of built-up area is obviously larger than that of population. Its annual increase rate is $5.05 \%$, which is obviously higher than that of population $2.08 \%$. The following will analyze whether the development relationship between population and land is reasonable from two levels of time and space.

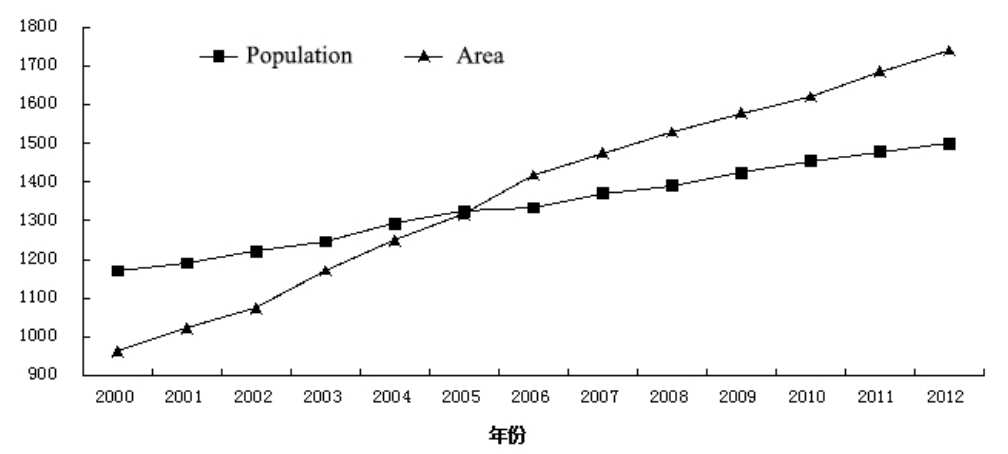

Fig. 1 The increase of urban population and land in Hebei

Research on Features of Allometry. Allometry was a geometric measurement method first applied in the field of biology. Now it is applied in the research on urban development as well as the research on scale features of population and land in the process of urban development, reflecting the longitudinal growth law of urban system in the process of historical development ${ }^{[9]}$. P represents urban population and L represents urban built-up area. P and L generally have the following power exponential relationship:

$$
\mathrm{L}=\alpha \mathrm{P}^{\beta}
$$

Wherein: $\alpha$ is proportionality factor; $\beta$ is scaling exponent ${ }^{[10]}$.

Make a regression analysis of power function and linear function of urban population and built-up area from 2000 to 2012 (Figure 2), and then Table 1 is obtained.

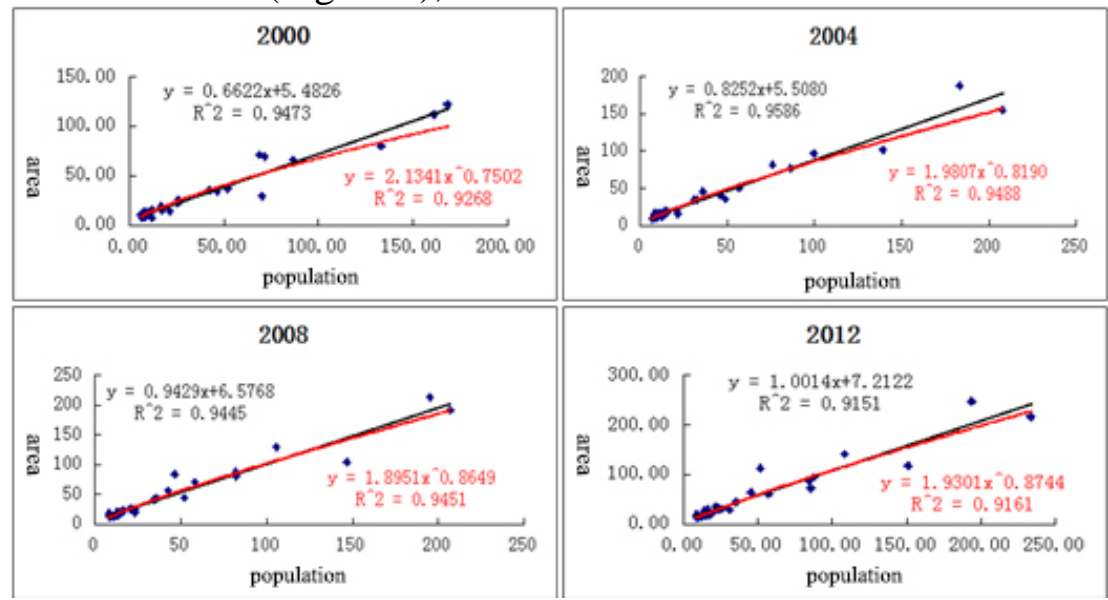

Fig. 2 Models of urban land-population allometric growth in Hebei (2000-2012) 
Tab. 1 The table of goodness-of-fit test of allometric grow in prefecture-level cities in Hebei

\begin{tabular}{ccc}
\hline Year & \multicolumn{2}{c}{ Goodness-of-fit } \\
\hline 2000 & Power function & Linear function \\
2001 & 0.9268 & 0.9473 \\
2002 & 0.9678 & 0.9634 \\
2003 & 0.9498 & 0.9463 \\
2004 & 0.9281 & 0.9445 \\
2005 & 0.9488 & 0.9586 \\
2006 & 0.951 & 0.9563 \\
2007 & 0.9378 & 0.9428 \\
2008 & 0.9474 & 0.9498 \\
2009 & 0.9451 & 0.9445 \\
2010 & 0.9397 & 0.939 \\
2011 & 0.926 & 0.9266 \\
2012 & 0.9329 & 0.9308 \\
\hline
\end{tabular}

The key of allometric model is to inspect the value of parameter $\beta$. On the assumption of equal dimension between $\mathrm{P}$ and $\mathrm{L}$, it is generally considered that:

The value of $\beta$ greater than 1 , namely positive allometry, indicates that the growth of urban land is faster than that of urban population, and the urban population density decreases;

The value of $\beta$ smaller than 1 , namely negative allometry, indicates that the growth of urban land is lower than that of urban population, and the urban population density increases;

If the value of $\beta$ is 0 , it indicates no change in urban population density;

If the value of $\beta$ is 1 , namely the same growth rate of urban population and land, it indicates a linear relationship between their growths.

In the research on allometry, only if the standard value of scaling exponent is reasonable, and the population and land dimensions reach the maximum balance, the analysis of relative growth relationship between built-up area and population in the urban system will be more reasonable. The scaling exponent used in this paper was first proposed by scholars such as Liu Yan'guang. Its standard value that is applicable to China's situation is $0.85^{[11-13]}$.

Table 3 shows the sign of degradation of allometry relationship from 2000 to 2007. On the one hand, it may be caused by the difference between statistical range of urban population and statistical range of built-up area. Therefore, from the accurate angle of research on cities, it is necessary to form the basic data about urban population and land equipotent in territory. On the other hand, it indicates that an ordered and reasonable urban system has not yet been formed in Hebei province. Affected by various factors such as resource and location, there is an obvious regional difference in the urban development of the whole province, which is specifically reflected in northern regions such as Zhangjiakou and Chengde and eastern regions such as Cangzhou and Hengshui. Due to factors such as location and landform, the urban development is lower. Since 2008, the allometric feature of urban system has gradually been significant, and the urban system has gradually become complex and perfect. The reason is that in recent years, Hebei province has begun to enhance the economic development and urban construction in regions at a lower development speed.

The research on allometric scaling exponent in Table 4 shows that the development of urban system from 2000 to 2006 (linear function till 2005) is in a negative allometry phase, namely, the population growth rate is larger than land growth rate. At this point, cities longitudinally develop towards high level and population density shows a rising trend. From 2007 (linear function from 2006), the scaling exponent exceeds the standard value 0.85. The development of urban system enters in a positive allometry phase, namely, the land growth rate is larger than population growth rate. At this point, cities horizontally develop towards "flattening" and the population density shows a reducing trend. The reasonable urban development mode is that with the expansion of urban scale, cities should longitudinally develop towards high level when the area of urban infrastructure is smaller. However, at present, the development trend of urbanization of the whole province is in an 
opposite way, so the urban development of Hebei province does not make intensive use of land ${ }^{[2]}$.

Research on Urban Land Expansion Coefficient. After an allometric analysis of previous data of cities, it is found that the fitting results are not satisfactory. Therefore, the indicator-urban land expansion coefficient is used to analyze the relationship between population and land from the spatial level. Land expansion coefficient refers to the ratio of urban land growth rate to urban population growth rate in a certain period. Its expression is as follows:

$$
\mathrm{K}=\mathrm{GR} / \mathrm{PR} \times 100 \%
$$

Wherein, $\mathrm{K}$ is urban land expansion coefficient, GR is the annual average growth rate of urban built-up area, and PR is the annual growth rate of urban population ${ }^{[3]}$. Table 2 shows the urban land expansion coefficients from 2000 to 2012.

Tab. 2 The coefficient table of urban land expansion

\begin{tabular}{|c|c|c|c|c|c|}
\hline City & $\begin{array}{l}\text { Expansion } \\
\text { coefficient }\end{array}$ & $\begin{array}{l}\text { Population density } \\
2012\left(/ \mathrm{km}^{2}\right)\end{array}$ & City & $\begin{array}{l}\text { Expansion } \\
\text { coefficient }\end{array}$ & $\begin{array}{l}\text { Population density } \\
2012\left(/ \mathrm{km}^{2}\right)\end{array}$ \\
\hline Chengde & 6.159 & 702 & Gaocheng & 1.232 & 1455 \\
\hline Tangshan & 5.179 & 1605 & Nangong & 1.211 & 730 \\
\hline Jizhou & 4.065 & 1228 & Qinhuangdao & 1.203 & 2626 \\
\hline Baoding & 3.468 & 3879 & Huanghua & 1.143 & 953 \\
\hline Handan & 3.123 & 3745 & Wuan & 1.120 & 2587 \\
\hline Cangzhou & 2.845 & 3352 & Gaobeidian & 1.065 & 4450 \\
\hline Luquan & 2.188 & 1388 & Bazhou & 0.807 & 1971 \\
\hline Anguo & 2.185 & 1136 & Zunhua & 0.798 & 2538 \\
\hline Renqiu & 2.073 & 5151 & Jinzhou & 0.702 & 1153 \\
\hline Hengshui & 1.968 & 1322 & Shenzhou & 0.657 & 2044 \\
\hline Dingzhou & 1.892 & 8325 & Sanhe & 0.620 & 1196 \\
\hline Zhuozhou & 1.845 & 5002 & Hejian & 0.589 & 2507 \\
\hline $\begin{array}{l}\text { Shijiazhu } \\
\text { ang }\end{array}$ & 1.796 & 8210 & Xinle & 0.181 & 1803 \\
\hline Xinji & 1.454 & 1303 & Langfang & -1.861 & 1788 \\
\hline Xingtai & 1.360 & 7818 & Shahe & -2.226 & 2559 \\
\hline Qianan & 1.351 & 1824 & Botou & & 7659 \\
\hline $\begin{array}{c}\text { Zhangjiak } \\
\text { ou }\end{array}$ & 1.323 & 2307 & Province & 2.404 & 2411 \\
\hline
\end{tabular}

According to the research of China Institute of Urban Planning and Design (1989): the reasonable value of China's urban land expansion coefficient is 1.12, namely, when the urban population increases by $1 \%$, the built-up area increases by about $1.12 \%$. When the value is less than 1.12 , it indicates that the urban construction land is tight; when the value is greater than 1.12, it indicates that urban construction area is too large. According to actual situation of Hebei province, the expansion coefficients are divided into three levels: expansion coefficients greater than 2 belong to Level I, representing that the built-up area expansion is faster than urban population expansion and the land utilization is lower; expansion coefficients between 1 and 2 belong to Level II, which is a relatively coordinated range; expansion coefficients smaller than 1 belong to Level III, representing that the built-up area scale is obviously smaller than urban population scale and the urban land is tight.

Hebei province has 33 cities (11 prefecture-level cities, 22 county-level cities). 9 cities are at Level I, with the land expansion coefficient higher than 2, exceeding relatively coordinated range, indicating that their construction land expansion is fast. 14 cities are at Level II, indicating that the development of their urban land and population is relatively reasonable. 9 cities are at Level III, with the land expansion coefficient obviously lower than reasonable value, indicating that land growth range is smaller than population growth range. Data about Langfang, Shahe and Botou is abnormal: data about Langfang and Shahe is negative, and the population growth rate of Botou is 0 . A problem is found after data of the three cities is analyzed, namely, the urban population data is too 
high in 2000, which has a big gap with the following data. This is caused by different statistical calibers in different years. 5 of 11 prefecture-level cities are at Level I, and there is a phenomenon of land waste. 5 cities are at Level II, which are in a relatively coordinated phase. 22 county-level cities are located in central regions such as Shijiazhuang, Hengshui, Cangzhou and Baoding, 4 of which are at Level I, 9 of which are at Level II, and the other 9 are at Level III. Comparison between the prefecture-level cities and county-level cities shows that the ratio of prefecture-level cities at Level II to these at Level III is 55\%, while the ratio of county-level cities is $81 \%$. Thus, the larger the city is, the faster the built-up area expansion is than urban population expansion, and the more serious the phenomenon of land waste is.

Expansion coefficient cannot express the concept of urban land per capita. To more comprehensively analyze relationship between urban population and land, the urban population density indicator data is added for comparison. Data in Table 5 shows that the urban land expansion coefficient of the whole province is 2.404 ; population density is 2411 persons $/ \mathrm{km}^{2}$, nearly similar to the national average value of 2378 persons $/ \mathrm{km}^{2}$. Specifically speaking, (1) among 11 cities with expansion coefficients not higher than 1.12, the population density of Gaobeidian City is significantly higher than the provincial average value of 2411 persons $/ \mathrm{km}^{2}$, reaching 4450 persons $/ \mathrm{km}^{2}$; the population density of Huanghua City is significantly lower than the provincial average value, only 953 persons $/ \mathrm{km}^{2}$; (2) Among 21 cities with expansion coefficient larger than 1.12, the expansion coefficients of Chengde, Tangshan and Jizhou far exceed 1.12, and the expansion coefficient of Chengde is the largest, reaching 6.159. Moreover, the population densities of above three cities are significantly low, and the population density of Chengde with the largest expansion coefficient is the lowest in the whole province, only 702 persons $/ \mathrm{km}^{2}$, indicating the irrational use of land to a certain extent. In addition, the population density of Nan'gong City with the urban expansion coefficient close to a reasonable value is significantly lower, only 730 persons $/ \mathrm{km}^{2}$. However, it can be seen that in most region of Hebei province, there is a phenomenon of large construction land area and low land utilization. It is related to land economy implemented by local governments in recent years. Driving GDP increase by selling land promotes the excessively rapid growth of construction land.

\section{Discussion}

Allometry and urban land expansion coefficient can be used to analyze their growth ratio relationship, and reflect the coordination between built-up area expansion and population growth. The fitting result of allometry through horizontal analysis is not satisfactory, so urban land expansion coefficient is introduced, but they cannot reflect the factor-status of urban population density. Therefore, the indicator-urban population density is used for comparison, so that the status of urban scale development can be analyzed in a more dimensional and comprehensive manner.

The urban system of Hebei province is not perfect, it lacks mega-cities and the urban scale is commonly small. To develop itself with both advantages and disadvantages brought by the adjacency to Beijing and Tianjin, Hebei province needs to link its planning with those of Beijing and Tianjin, seize opportunities, and continue to develop large cities and vigorously development a batch of medium cities so as to driving the development of small cities. Separated by Beijing and Tianjin, Zhangjiakou and Chengde have few contacts with other cities in Hebei province. In addition, the development of Cangzhou and Hengshui is significantly backward. Therefore, it is necessary to arrange the common development of north-south regions and west-east regions, make a rational layout, change the traditional development mode and concept, reduce pollution projects, and build livable eco-cities. The land expansion rate of most cities in Hebei province is higher than population growth rate, and it is especially significant in recent years from the vertical perspective. From the horizontal perspective, the land expansion coefficients of nearly two-thirds of cities exceed the reasonable value and the expansion coefficients of prefecture-level cities are large. Except of few cities, the overall urban population density of Hebei province is low. Therefore, for urban development, it is necessary to abandon the "over-spreading” mode, and ensure efficient, economical and intensive land utilization while meeting the requirements of urban infrastructure 
construction and environmental protection.

\section{Bibliography}

[1] Cheng Jieru. Research on Urbanization Development and Land Utilization of Meizhou City [J]. Economic Geography, 2009 (10): 1665-1670.

[2] Xie Wenhui, Deng Wei. Urban Economics [M] Beijing: Tsinghua University Press, 1996.

[3] Tan Shukui, Song Haipeng. Matching Status of Land Urbanization and Population Urbanization [J]. Urban Problems, 2013 (11): 2-6.

[4] Zhao Cen, Feng Changchun. Research on Relationship between Urban Population and Urban Land in The Process of China's Urbanization [J]. Urban Studies, 2010, 17 (10): 113-118.

[5] Zhu Fengkai, Zhang Fengrong et al. Coordination Degree of China's Land and Population Urbanization from 1993 to 2008 and Regional Differences [J]. Progress in Geography, 2014, 33 (5): 647-656.

[6] Ruan Xiangqian, Zhang Li. Comparative Analysis of Development of Xinjiang Population Urbanization and Land Urbanization [J]. Xinjiang State Farms Economy, 2014 (3): 42-46.

[7] Li Mingyue, Hu Zhuzhi. Comparison between Population Urbanization Rate and Land Urbanization Rate in Guangdong Province [J]. Urban Problems, 2012 (4): 33-36.

[8] Guo Shihong, Wang Fuxi et al. Research on Space-Time Fitting Coordination Relations between Population Urbanization and Land Urbanization in Shandong Peninsula [J]. Economic Geography, 2014,34 (3): 72-78.

[9]Lee Y. An allometric analysis of the US urban system;1960-1980[J].Environment\&Planning A,1989,21(4).

[10] Liu Jisheng, Chen Yanguang. Discussion on Population- Area Allometric Features of Regional Cities. Scientia Geographica Sinica, 2005, 25 (2): 135-141.

[11] Chen Yanguang, Xu Qiuhong. Fractal Geometric Model of Population-Area Allometry of Regional Cities- Revision and Development of Nordbeck-Dutton Theory of Allometry of Urban System [J]. Journal of Xinyang Normal University (Natural Science), 1999, 12 (2): 198-203.

[12] Li Xun, Chen Gangjiang, Xu Xueqiang. Analysis of China's Urban Allometry [J] Acta Geographica Sinica, 2009, 64 (4): 399-407.

[13] Li Haoxu, Song Junzhuo, Jie Yaowen, Wang Xiangqian. Analysis of Urban Expansion in Ganzhou District, Zhangye City from 1959 to 2009 [J]. Remote Sensing Technology and Application, 2011, 26 (5): 584-589. 